\title{
COVID-19: What we Already Learnt
}

\author{
National Research Council of Italy@ Milano Polytechnic University. \\ Designated scientific attache to the Italian Ambassador in Belgrade. \\ Correspondin\& Author Information \\ Diego Liberati
National Research Council of Italy @ Milano Polytechnic University.
Designated scientific attache to the Italian Ambassador in Belgrade.
}

Diego Liberati*

Received: June 22, 2020; Accepted: June 23, 2020; Published: June 25, 2020

Copyright: (C) 2020 ASRJS. This is an openaccess article distributed under the terms of the Creative Commons Attribution 4.0 International license.

Citation: Diego Liberati. COVID-19: What we Already Learnt. Med Clin Res Open Access, 2020;1(1):1-2.

World has almost stopped fearing for COVID-19: a cold born last winter, as 19 reminds, whose effects are apparent in this 2020: until now less dead than in the same 4 first months of the previous years, globally, thanks to the mild winter (but same people complains also about light global warming, forgetting that a new glaciation will soon or later happen :)

Nevertheless most economies stopped, thus lot of people will die. On hunger as usual, but who cares? Hunger do not affect rulers, thus why to care of? Nor abortion: a fetus does not vote. yet! Nor malaria: rulers are rich enough to get Metakelfin... but a cold, whose side effect in an infinitesimal cohort of susceptible are a difficult pneumonia, does scare even them, as did AIDS, interfering with their habit of sexual promiscuity.

In fact, COVID-19 appears to be quite affine to a particular protein, mainly expressed in elderly males, in turn affine to lungs, implying in such tiny cohort of susceptible ones a pneumonia, whose treatment in hospital deprived of hygienic care - because of the steeling of former Lombardy president, already in jail because of that, and friends - then full of antibiotic-resistant bacteria, definitively killed them. In south of Italy, bigger stealing did even undermake intensive care unit this paradoxically saving lives not allowing hospitalization.

Caring at home, assisted by technical tools and specialized personnel, like modern health theory finally preaches and experiment, would have been better and cheaper, but less keen to steel by politicians: new ones pretend to be honest, which would be nice. But competence is even more important: lack of that is even more obnoxious than lack of honesty, that is also cheaper to loose when one is so little competent that she/he has nothing to loose to let somebody else buy her/ him!

Leading states, like Switzerland, Singapore, South Corea, did behave more rationally: a better strategy would have been, and probably still is, to confine only susceptible ones, trying to measure the famous protein besides gender and age, to protect them, letting everybody else to freely circulate, letting world to reach earlier the natural flock immunity without severe consequences then freeing also susceptible ones: Switzerland is thus almost over, but obliged to keep frontiers close because of the less clever behavior of the confining states. Vaccine is in this case of rapidly mutating virus, a chimera, often used just again for commercial reason. This does not mean of course that every vaccine is unuseful: not only poliomyelitis for instance has been quite eradicated for a while thank to the useful vaccination thus obligatory!

Nevertheless, the present expensive colossal lockdown is a great experiment not just on social side, testing the compliance of people to obey to irrational orders, like in compulsory militar service, but also on modeling side, simulating in real life a prolongation of the duration of the epidemic period: being almost everybody getting such cold as usual, and as usual having a few symptomatic and a very few susceptible complicated, the lockdown has the effect to lower the amplitude of the contagious thus prologuing its duration, - - - - - - - - - - - - - - - - - - - - - - - - - - - - - - - - - - - - - - - - - - - 
being Area Under the Curve almost not affected by lockdown.

Modeling dynamics of mortality and economic consequences of lockdown in order to forecast effects and possibly control them with a wiser strategy will thus be an important subject of nowadays research, whose yielding will be hopefully soon discussed in a more technical paper.World has almost stopped fearing for COVID-19: a cold born last winter, as 19 reminds, whose effects are apparent in this 2020: until now less dead than in the same 4 first months of the previous years, globally, thanks to the mild winter (but same people complains also about light global warming, forgetting that a new glaciation will soon or later happen :)

Nevertheless most economies stopped, thus lot of people will die. On hunger as usual, but who cares? Hunger do not affect rulers, thus why to care of? Nor abortion: a fetus does not vote. yet! Nor malaria: rulers are rich enough to get Metakelfin... but a cold, whose side effect in an infinitesimal cohort of susceptible are a difficult pneumonia, does scare even them, as did AIDS, interfering with their habit of sexual promiscuity.

In fact, COVID-19 appears to be quite affine to a particular protein, mainly expressed in elderly males, in turn affine to lungs, implying in such tiny cohort of susceptible ones a pneumonia, whose treatment in hospital deprived of hygienic care - because of the steeling of former Lombardy president, already in jail because of that, and friends - then full of antibiotic-resistant bacteria, definitively killed them. In south of Italy, bigger stealing did even undermake intensive care unit this paradoxically saving lives not allowing hospitalization.
Caring at home, assisted by technical tools and specialized personnel, like modern health theory finally preaches and experiment, would have been better and cheaper, but less keen to steel by politicians: new ones pretend to be honest, which would be nice. But competence is even more important: lack of that is even more obnoxious than lack of honesty, that is also cheaper to loose when one is so little competent that she/he has nothing to loose to let somebody else buy her/ him!

Leading states, like Switzerland, Singapore, South Corea, did behave more rationally: a better strategy would have been, and probably still is, to confine only susceptible ones, trying to measure the famous protein besides gender and age, to protect them, letting everybody else to freely circulate, letting world to reach earlier the natural flock immunity without severe consequences then freeing also susceptible ones: Switzerland is thus almost over, but obliged to keep frontiers close because of the less clever behavior of the confining states. Vaccine is in this case of rapidly mutating virus, a chimera, often used just again for commercial reason. This does not mean of course that every vaccine is unuseful: not only poliomyelitis for instance has been quite eradicated for a while thank to the useful vaccination thus obligatory!

Nevertheless, the present expensive colossal lockdown is a great experiment not just on social side, testing the compliance of people to obey to irrational orders, like in compulsory militar service, but also on modeling side, simulating in real life a prolongation of the duration of the epidemic period: being almost everybody getting such cold as usual, and as usual having a few symptomatic and a very few susceptible complicated, the lockdown has the effect to lower the amplitude of the contagious thus prologuing its duration, 